\title{
Health as Balance: A Conceptual Study
}

\author{
Abraham Rudnick ${ }^{1,2}$ \\ ${ }^{1}$ Northern Ontario School of Medicine, Thunder Bay, Canada \\ ${ }^{2}$ Thunder Bay Regional Health Sciences Centre, Thunder Bay, Canada \\ Email: harudnick@hotmail.com
}

How to cite this paper: Rudnick, A. (2017) Health as Balance: A Conceptual Study. Health, 9, 1000-1006.

https://doi.org/10.4236/health.2017.97072

Received: May 18, 2017

Accepted: July 4, 2017

Published: July 7, 2017

Copyright $\odot 2017$ by author and Scientific Research Publishing Inc. This work is licensed under the Creative Commons Attribution International License (CC BY 4.0).

http://creativecommons.org/licenses/by/4.0/

\begin{abstract}
The notion of health as balance has influenced health care for long. It is not known in what ways, if any, this notion has influenced health research, and whether such influence is helpful. I conduct here a conceptual (rather than an empirical) study to address the unsolved problem whether the notion of health as balance (rather than balance restoring health), specified in various established ways, such as balance between internal and external forces, may be helpful when used in health research. I find that the notion of health as balance has challenges, such as when it focuses on homeostasis, as norms of health are not specified by such a notion. Yet the notion of self-organization has promise as a helpful specification of the notion of health as balance. Health research may benefit from the innovation of use of the notion of health as self-organization, such as by prioritizing host and person (rather than agent) in physical and mental health research and using complexity theory and related methods in relation to self-organization.
\end{abstract}

\section{Keywords}

Allostasis, Balance, Health, Homeostasis, Self-Organization

\section{Introduction}

Health care such as medicine has used the notion of balance as a reference point from early on. For example, ancient Greek and Roman medicine referred to health as a balance of humours, as have medieval European and Arabic medicine [1]. Indian, Chinese, Japanese, and other Eastern Asian medicines have also aspired to balance, such as by use of the notion of yin and yang [2]. North American aboriginal medicine has aimed at balance through the notion of harmony as manifest in the concept of the medicine wheel [3], similarly to notions of health in Australasian aboriginal medicine [4]. Although it may not be as explicit in African traditional medicine [5], much of it seems to assume health as balance. Western allopathic medicine is grounded in balance-associated $20^{\text {th }}$ century no- 
tions such as homeostasis [6], which was influenced by Claude Bernard's 19th century introduction of the notion of the stability of the internal environment [7].

The notion of health as balance (rather than balance restoring health) may not matter much in practice if it does not influence much of health care. The notion of ill-health has evidently influenced much of health care, in historical, allopathic, traditional, and complementary and alternative medicine (CAM), both in prevention and in treatment (and arguably also in health promotion and in rehabilitation). Much of ill-health has been viewed as the disruption of health as balance, such as in the case of auto-immune disorders in regards to balance primarily within the body and in the case of infectious diseases in regards to balance primarily between the body/person and his/her environment (and most other disorders, such as cancer, combining these two aspects of balance). Thus, it seems that on the face of it, the notion of health as balance has influenced much of health care over time and across places and cultures.

It is not as known in what ways, if any, has the notion of health as balance influenced health research (as distinct from health care), and whether such influence is helpful. Admittedly, Claude Bernard based much of his pioneering research in physiology and pathophysiology, such as in relation to carbohydrate metabolism, on his notion of health as the stability of the internal environment, which was evidently helpful for him so much so that he eventually published a whole book on general research methodology informed by this notion and his related research [7]. Yet it is not clear to what extent modern and contemporary health research has followed suit, and whether it should. Furthermore, considering that the notion of health as balance seems to be prevalent in CAM, as well as in integrative care (integrating CAM with allopathic medicine), it is not clear in what ways if any CAM research uses it, and if it does whether it is helpful, particularly as this notion of health has been said to not lend itself well to rigorous health-particularly clinical-research, partly due to the non-linearity of phenomena involved in balance (recently developed complexity theory notwithstanding [8]). I conduct here a conceptual analysis [9] (rather than an empirical study) to address the unsolved problem whether the notion of health as balance, specified in various ways (particularly as self-organization), may be helpful when used in CAM research and other health research.

\section{The Notion of Health as Balance}

Before delving into an analysis of the notion of health as balance and its research implications, it is important to note that there are other notions of health that have influenced health care and health research. Generally, notions of health can be classified thus [10]: a. negative versus positive, with negative notions of health presenting health as merely the absence of disorder, and positive notions of health presenting health as not merely the absence of disorder, as is the case with the World Health Organization's definition of health as a state of complete physical, mental and social well-being [11]; b. common versus ideal, with no- 
tions of health as common presenting health as a (statistically) common state or set of states [12], and notions of health as ideal presenting health as an (evolutionary or otherwise) ideal-or at least optimal (for given circumstances) - state or set of states [13]; c. mechanistic versus holistic, with mechanistic notions of health presenting health as determined by parts of systems, as is the case supposedly with an injury causing ill-health, and holistic notions of health presenting health as determined by interactions of parts within systems and across systems, as is the case arguably with psychiatric disorders that demonstrate faults in interactions of various parts of the brain and in interactions between the person and his or her environment [14]. The notion of health as balance is related to and perhaps equivalent to a holistic notion of health.

Although there is no explicit agreement across time, places and cultures on what balance means, at a minimum it seems to refer to sustained effective interaction of parts or components of a system. What is considered sustained enough, effective enough, and included in or excluded from a particular system, seems to be determined by the persons addressing the system. This may partly explain why there is no clear agreement on the notion of health. Still, it seems clear enough that the notion of health as balance involves at least an assumption of optimal amounts of parts of the person's system and of their interactions, either of which may fluctuate over time; for example, health as balance may be balance between internal and external forces such as between immunity and infection (both of which may be beneficial or harmful, depending on extent and balance with other forces, e.g., probiotics are external yet beneficial and autoimmunity is internal yet harmful, as is cancer). Therefore, ill-health, according this notion, will consist of more than optimal and/or less than optimal amounts of parts of the person's system and of their interactions. Interestingly, an alternative health care approach such as orthomolecular medicine, known for its prescription of mega-doses of vitamins, seems to largely ignore the possibility that it is not just less than optimal but also more than optimal amounts of vitamins and other chemicals in the body that may lead to ill-health [15], which raises the reasonable and important possibility that it can be iatrogenic as well as therapeutic.

The notion of health as balance is rather general. For analysis, it is helpful to be more specific, although the risk of any specification is that it may exclude some interpretations of the notion. Perhaps a standard interpretation of health as balance would do, such as homeostasis. A challenge with the concept of homeostasis is that in addition to being an allopathic concept, at least historically, which suggests that it may not easily apply to CAM, it is also recently criticized for not addressing various situations, such as health related phenomena that are anticipatory of health adversity rather than reactive to it. This is particularly relevant to beings such as humans whose brain can determine in advance health reactions (behavioural, physiological and other), both consciously and unconsciously, e.g., by means of anticipatory anxiety and the autonomic nervous system, respectively; this is termed allostasis [16] [17] [18] [19]. Perhaps more importantly, homeostasis is not independent conceptually as a notion of health: 
"health cannot be the homeostatic maintenance of just any state. Some additional criteria must specify which states an organism's homeostatic mechanisms must maintain for it to be healthy. As we indicated, homeostasis requires a reference to some set points that an organism's compensatory responses are supposed to maintain, and these set points are not established by the notion of homeostasis itself but must be specified independently of it." ([20], p. 71).

Furthermore, "We find many biological functions that are not related to homeostatic regulation ... one must at least admit other criteria for regulation than homeostasis ... a norm is required that delineates proper from impaired regulation.” ([21], p. 126). The same argument holds for allostasis, unless we believe in evolution as all-determining for such norms, which some allostasists have endorsed, but I will reject here due to insufficient evidence in support of such a belief. More generally, even regulation in itself requires norms independent of it to characterize health, as has been shown in relation to maladaptive regulation reactions such as the General Adaptation Syndrome, which may start adaptively in reaction to stress but becomes maladaptive when it continues for long [22]. Thus, homeostasis, allostasis and more generally regulation seem insufficient and hence inadequate as specifications of the notion of health as balance.

\section{The Notion of Health as Self-Organization}

Another specification of the notion of health as balance is health as self-organization, characterized as processes resulting in relatively invariant properties of an organism in differing and sometime challenging conditions, within certain limits of viability ([10], p. 84). Although this notion may seem similar to homeostasis, allostasis and regulation, its formal focus on self, complex as that may be, facilitates norming of health in relation to self-biological, psychological and perhaps other. In particular, complexity theorists have been developing relevant theoretical frameworks, simulation models and other research approaches in order to study complexity notions related to health. This started in the mid- $20^{\text {th }}$ century with approaches influenced by cybernetics, addressing self-organizing systems in general-such as crystals, in addition to living systems that have various states of equilibrium, each state depending on an adaptation to changed circumstances or more generally to changed environmental and other conditions (such as necessarily occurring wear and tear) ([23], p. 275). Currently, this research continues with characterization of self-organization as "processes of selfmaintenance, such that a trait has (or serves) a specific function, to the extent that the trait contributes to the maintenance of the biological organization to which it belongs." ([24], p. 87). In practical terms, self-organization and its disruptions may consist most generally of self-creation and its disruptions, such as embryogenesis and teratogenesis, respectively, and of self-repair and its disruptions, such as wound healing and abscess formation, respectively [10]. This approach can be applied not only to physical health but also to mental health (as much as these two aspects of health can be distinguished), such as in relation to 
recovery of people with schizophrenia [25].

Arguably, a limitation is that self-organization may be determined by evolution, and hence possibly reduced to it. Whether determination equals reduction or not, evolutionary mechanisms of life seem to be a possible and perhaps necessary, but certainly not sufficient, set of explanations of self-organization. For example, in evolutionary theory the environment is central; whereas in complexity theory properties of the system, such as its internal structure, largely unrelated to its environment, are central [8].

What may be some research implications of such a notion of health as self-organization? First, norms of health of self-organization should be clarified, e.g., what is considered healthy in what circumstances (such as, perhaps obviously, mild but not severe fever in infectious disorders, and no fever in non-infectious disorders), so that health research can study them distinctly as much as possible. Second, general and special processes of health as self- organization should be addressed, e.g., perhaps building on learnings from past General Adaptation Syndrome research [22] among others. Such a focus may facilitate more research-biological as well as psychosocial-on health promotion. This is clearly needed, particularly in biopsychosocial complex situations such as post-partum [26]. It also aligns well with CAM's emphasis on healthy living, particularly with CAM that is influenced by Asian traditional medicine. Of note is that some Asian traditional medicine and related CAM has moved towards more pathology oriented thinking and research, perhaps due to Western allopathic medicine's influence, which seems to be the case with much of Kampo ([27]; 28, p. 2); Kampo research may benefit from reprioritizing health promotion based on the notion of health as self-organization. Third, in relation to the second implication noted above, a focus on health as self-organization in CAM and other health research may redirect intellectual, financial and other resources to further address the biological and psychological self (host and person, respectively); indeed, there is recognition in CAM research that such a focus is needed, for example: "In the modern version of Kampo, the host condition is assigned a high value, while the foreign pathogen is addressed by Western biomedicine. Therefore, the host energy is of greater importance." ([28], p. 3). Admittedly, Western allopathic medicine has moved from a focus on the (pathogenic) agent to prioritizing the host in some areas, such as in immune system research, as has some traditional medicine for long. Yet some areas such as Western mental health research have only recently started to prioritize the person and his or her self-organization (termed recovery in the mental health field), addressing both the individual [29] and his or her environment-especially the social environment or community [30]. It remains to be seen to what extent CAM will align with this direction in relation to mental health research.

\section{Conclusion}

The notion of health as balance has challenges, such as when it focuses on homeostasis, as norms of health are not specified by such a notion. The notion of 
self-organization holds promise as a helpful specification of the notion of health as balance. CAM and other health research may benefit from the innovation of use of the notion of health as self-organization, such as by prioritizing host and person in physical and mental health research, and possibly by using complexity theory and its methods in relation to self-organization.

\section{Acknowledgements}

This work was supported in part by a visiting scholarship awarded by the Brocher Foundation, Hermance, Switzerland.

\section{Conflict of Interests}

The author declares that he has no conflict of interests regarding the publication of this paper.

\section{References}

[1] Horden, P. and Hsu, E., Eds. (2015) The Body in Balance: Humoral Medicines in Practice. Berghahn, New York.

[2] Terasawa, K. (2004) Evidence-Based Reconstructions of Kampo Medicine: Part IIThe Concept of Sho. Evidence-Based Complementary and Alternative Medicine, 1, 119-123. https://doi.org/10.1093/ecam/neh022

[3] Primeaux, M.H. (1977) American Indian Health Care Practices: A Cross-Cultural Perspective. Nursing Clinics of North America, 12, 55-65.

[4] Durie, M., Milroy, H. and Hunter, E. (2009) Mental Health and the Indigenous Peoples of Australia and New Zealand. In: Kirmayer, L.J. and Valaskakis, G.G., Eds., Healing Traditions. The Mental Health of Aboriginal Peoples in Canada, University of British Columbia Press, Vancouver, 36-55.

[5] Mahomoodally, M.F. (2013) Traditional Medicines in Africa: An Appraisal of Ten Potent African Medicinal Plants. Evidence-Based Complementary and Alternative Medicine, 2013, Article ID: 617459.

[6] Cannon, W.B. (1932) The Wisdom of the Body. Norton, New York.

[7] Bernard, C. (1864) An Introduction to the Study of Experimental Medicine. Macmillan, New York.

[8] Kauffman, S.A. (2008) Reinventing the Sacred: A New View of Sciences, Reason, and Religion. Basic Books, New York.

[9] Yehezkel, G. (2005) A Model of Conceptual Analysis. Metaphilosophy, 36, 668-687. https://doi.org/10.1111/j.1467-9973.2005.00399.x

[10] Rudnick, A. (2002) The Notion of Health: A Conceptual Analysis. Israeli Medical Association Journal, 4, 83-85.

[11] Callahan, D. (1973) The WHO Definition of "Health". Hastings Center Studies, 1, 77-88.

[12] Boorse, C. (1977) Health as a Theoretical Concept. Philosophy of Science, 44, 542573. https://doi.org/10.1086/288768

[13] Nordenfelt, L. (1987) On the Nature of Health. Reidel, Dordrecht, The Netherlands. https://doi.org/10.1007/978-94-015-7768-7

[14] Fried, Y. and Agassi, J. (1983) Psychiatry as Medicine: Contemporary Psychotherapies. Martinus Nijhoff, The Hague, The Netherlands. 
https://doi.org/10.1007/978-94-009-6863-9

[15] Rudnick, A. (2010) Some Philosophical Reflections on Orthomolecular Psychiatry. Journal of Orthomolecular Medicine, 25, 1-4.

[16] Schulkin, J. (2003) Rethinking Homeostasis: Allostatic Regulation in Physiology and Pathophysiology. MIT Press, Cambridge, USA.

[17] Schulkin, J., Ed. (2004) Allostasis, Homeostasis, and the Costs of Physiological Adaptation. Cambridge University Press, Cambridge, UK.

[18] Sterling, P. (2012) Allostasis: A Model of Predictive Regulation. Physiology \& Behavior, 106, 5-15.

[19] Sterling, P. (2014) Homeostasis vs Allostasis: Implications for Brain Function and Mental Disorders. Journal of the American Medical Association Psychiatry, 71, 1192-1193. https://doi.org/10.1001/jamapsychiatry.2014.1043

[20] Dussault, A.C. and Gagne-Julien, A.-M. (2015) Health, Homeostasis, and the Situation-Specificity of Normality. Theoretical Medicine and Bioethics, 36, 61-81. https://doi.org/10.1007/s11017-015-9320-1

[21] Ulrich, K. (2011) Functions and Fixed Types: Biological and Other Functions in the Post-Adaptationist Era. Applied Ontology, 6, 125-139.

[22] Selye, H. (1956) The Stress of Life. McGraw-Hill, New York, USA.

[23] Ashby, W.R. (1962) Principles of the Self-Organizing System. In: Von Foerster, H. and Zopf Jr., G.W., Eds., Principles of Self-Organization: Transactions of the University of Illinois Symposium, Pergamon, London, 255-278.

[24] Saborido, C. and Moreno, A. (2015) Biological Pathology from an Organizational Perspective. Theoretical Medicine and Bioethics, 36, 83-95. https://doi.org/10.1007/s11017-015-9318-8

[25] Rudnick, A. (2008) Recovery from Schizophrenia: A Philosophical Framework. American Journal of Psychiatric Rehabilitation, 11, 267-278. https://doi.org/10.1080/15487760802186360

[26] Fowles, E.R., Cheng, H.R. and Mills, S. (2012) Postpartum Health Promotion Interventions: A Systematic Review. Nursing Research, 61, 269-282. https://doi.org/10.1097/NNR.0b013e3182556d29

[27] Keisetsu, O. (2010) Kampo: A Clinical Guide to Theory and Practice. Churchill Livingstone, Edinburgh, UK.

[28] Yakubo, S., Ito, M., Ueda, Y., et al. (2014) Pattern Classification in Kampo Medicine. Evidence-Based Complementary and Alternative Medicine, 2014, Article ID: 535146.

[29] Tondora, J., Miller, R., Slade, M. and Davidson, L. (2014) Partnering for Recovery in Mental Health: A Practical Guide to Person-Centered Planning. Wiley, Chichester, West Sussex, UK. https://doi.org/10.1002/9781118388532

[30] Nelson, G., Kloos, B. and Ornelas, J., Eds. (2014) Community Psychology and Community Mental Health: Towards Transformative Change. Oxford University Press, Oxford. 
Submit or recommend next manuscript to SCIRP and we will provide best service for you:

Accepting pre-submission inquiries through Email, Facebook, LinkedIn, Twitter, etc. A wide selection of journals (inclusive of 9 subjects, more than 200 journals)

Providing 24-hour high-quality service

User-friendly online submission system

Fair and swift peer-review system

Efficient typesetting and proofreading procedure

Display of the result of downloads and visits, as well as the number of cited articles Maximum dissemination of your research work

Submit your manuscript at: http://papersubmission.scirp.org/

Or contact health@scirp.org 